\title{
Seizure in infancy: not the usual suspect
}

\author{
Arushi Yadav ${ }_{1}^{1}$ Jogender Kumar ${ }^{2}$
}

'Radiodiagnosis and Imaging, SMS Medical College and Hospital, Jaipur, Rajasthan, India ${ }^{2}$ Pediatrics, Post Graduate Institute of Medical Education and Research, Chandigarh, India

Correspondence to Dr Jogender Kumar, jogendrayadv@gmail.com

Accepted 15 January 2019

\section{DESCRIPTION}

A term, $3.8 \mathrm{~kg}$ boy, born through meconium-stained liquor (MSL) was referred to a tertiary care hospital on day 4 of life in view of respiratory distress since birth. At admission, despite intubation and 100\% oxygen, he had preductal and postductal saturation of $94 \%$ and $83 \%$, respectively. In view of history of MSL and respiratory distress since birth, possibility of meconium aspiration syndrome (MAS) with persistent pulmonary hypertension of newborn (PPHN) was kept and was managed accordingly. Chest X-ray showed cardiomegaly with no evidence of MAS (figure 1). On clinical examination, he had an ejection systolic murmur over precordium, but there was no hepatomegaly or congestive cardiac failure. In view of the murmur, cardiomegaly on chest X-ray and clinical possibility of PPHN, bedside echocardiography was done. Echo showed structurally normal heart with marked tricuspid regurgitation (TR) with TR jet velocity of $4.8 \mathrm{~m} / \mathrm{sec}$, paradoxical movement of interventricular septum and dilated right atrium and ventricle consistent with PPHN. Baby was managed as per protocol; however, there was not much improvement. On day 5 of life, he had generalised tonic seizure, for which metabolic work-up (glucose, electrolytes, etc) was normal. Ultrasound cranium showed dilated lateral ventricles with a midline cystic structure showing high flow on colour Doppler suggesting vein of Galen malformation (VOGM). On auscultation, a loud bruit was heard over the anterior fontanelle. An MRI brain with angiography was done to confirm the diagnosis. The MRI (figures 2-4) showed a large aneurysmally dilated pouch-like midline hypointense lesion on T2-weighted images which on postcontrast scans showed complete

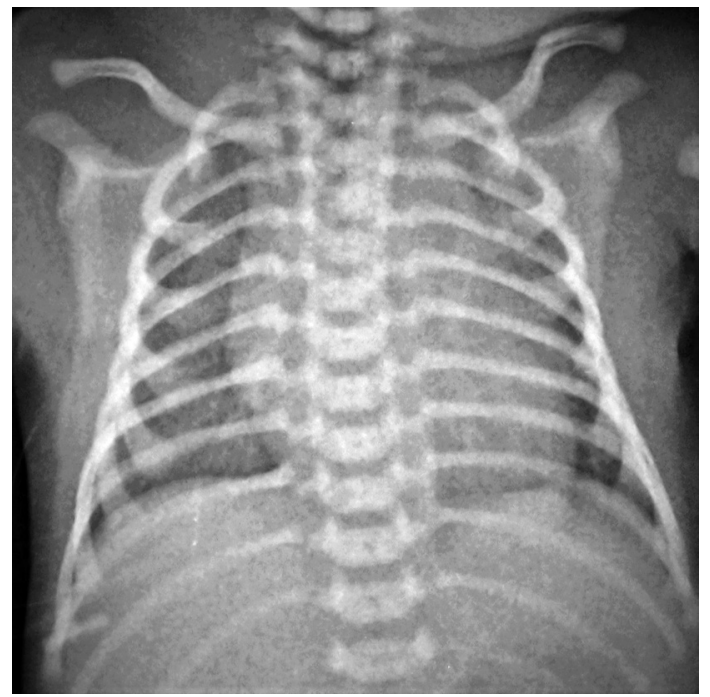

Figure 1 Chest X-ray showing cardiomegaly.

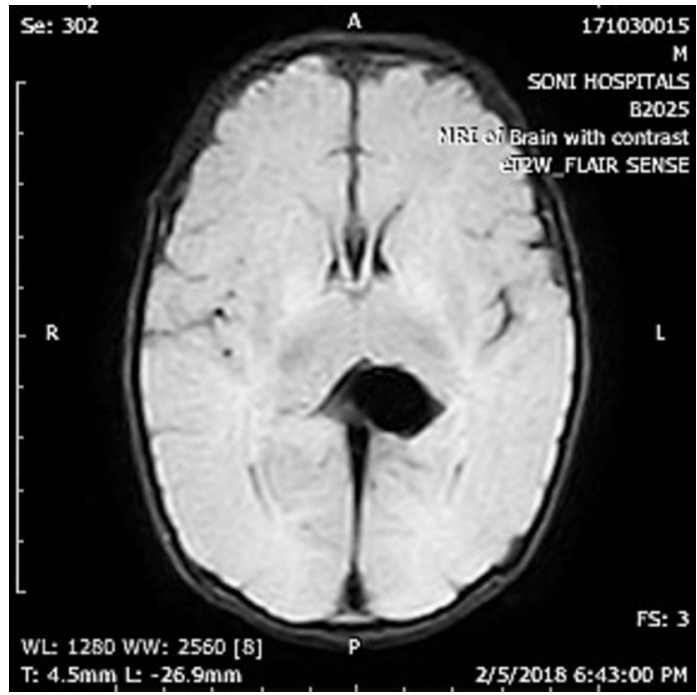

Figure 2 MRI brain (T2-weighted axial): midline hypointense aneurysmally dilated venous-pouch like lesion in quadrigeminal cisternal space.

contrast fill-up. It was drained by midline normally placed straight sinus, with dilatation of torcular herophili, and superior sagittal sinus. Right-sided posterior cerebral artery, posterior communicating artery and posterior choroidal artery were dilated. There was no intraparenchymal nidus with flow voids.

The baby was started on diuretics and underwent transarterial embolisation procedure on day 7 of life. Three days later, he was extubated successfully

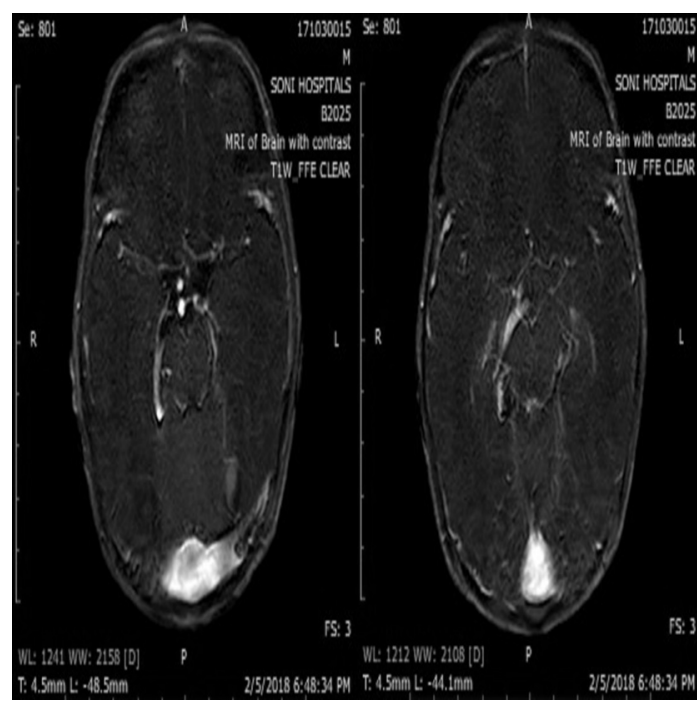

Figure 4 MRI brain (T1 postcontrast axial): dilated contrast-filled right posterior cerebral artery, right posterior communicating artery, right posterior choroidal artery. 
to room air and was stable. He was discharged on day 14 of life. The baby is registered in neurodevelopmental follow-up clinic for ongoing assessment of neuromorbidities.

In the index case, the chest radiograph showed normal parenchyma suggesting that the baby did not have MAS. However, there was echocardiography-proven PPHN without structural heart disease. The cardiomegaly may be due to volume overload secondary to high output VOGM, however clinically there was no congestive cardiac failure. In such cases, the other causes like the haemangioma, teratoma or large vascular malformation should be ruled out. VOGM is a rare congenital arteriovenous fistula, supplied by multiple arterial feeders draining into the median prosencephalic vein of Markowski. ${ }^{1}$ VOGM can be diagnosed antenatally on anomaly scan. Our case was an unsupervised pregnancy, therefore antenatal scan was not done. These neonates classically present with high-output cardiac failure or

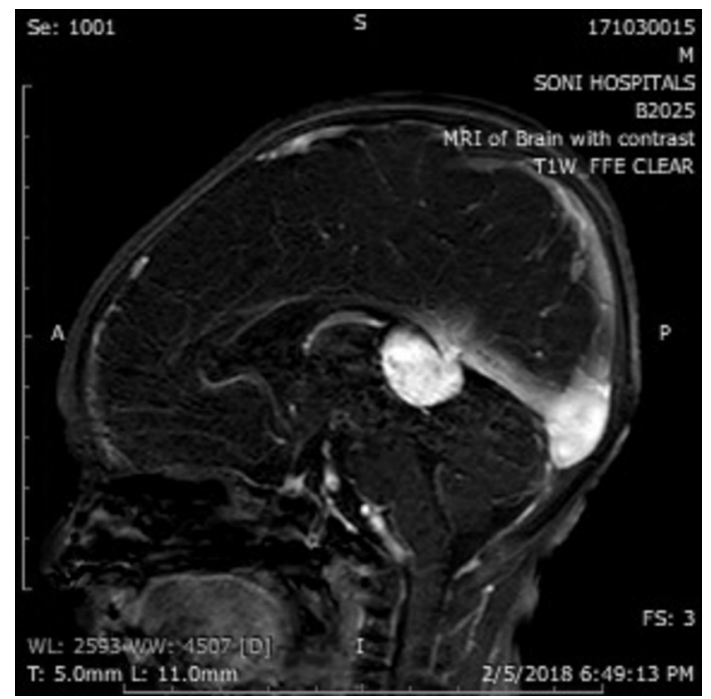

Figure 3 MR angiography (T1 postcontrast sagittal): midline lesion showing complete contrast fill-up and drainage in normally situated straight sinus. Torcular herophili, superior sagittal sinus appear dilated. gradually enlarging head. ${ }^{2}$ The bruit of VOGM is best heard over the anterior fontanelle or temporal region. Endovascular coil embolisation to occlude the feeder vessels is the treatment of choice and is associated with better outcome. ${ }^{3}$

\section{Learning points}

- In refractory persistent pulmonary hypertension of newborn, a search should be made for arteriovenous malformation (AVM), and clinical evaluation for hepatic and cerebral AVM should be done. A simple auscultation can lead to a timely diagnosis.

- Vein of Galen malformation (VOGM) may present as seizure in neonatal period.

- VOGM can be easily detected in anomaly scan, and antenatally diagnosed cases should be delivered in an appropriate setting.

- The VOGM may cause cerebral steal phenomenon leading to psychomotor disabilities and poor neurodevelopmental outcome.

- Early diagnosis and embolisation of VOGM are key for a better outcome.

Contributors AY and JK contributed equally in diagnosis, follow-up, literature search and writing of the manuscript. AY was involved in radiological work-up and reported all the radiological investigations. Both approved final version of the manuscript.

Funding The authors have not declared a specific grant for this research from any funding agency in the public, commercial or not-for-profit sectors.

Competing interests None declared.

Patient consent for publication Next of kin consent obtained.

\section{REFERENCES}

1 Mortazavi MM, Griessenauer CJ, Foreman P, et al. Vein of Galen aneurysmal malformations: critical analysis of the literature with proposal of a new classification system. J Neurosurg Pediatr 2013;12:293-306.

2 Chow ML, Cooke DL, Fullerton HJ, et al. Radiological and clinical features of vein of Galen malformations. J Neurointerv Surg 2015;7:443-8.

3 Szajner M, Pyra K, Poluha P, et al. [Endovascular treatment of vein of galen malformation with coils and onyx-case report]. Przegl Lek 2012;69:307-10.

Copyright 2019 BMJ Publishing Group. All rights reserved. For permission to reuse any of this content visit https://www.bmj.com/company/products-services/rights-and-licensing/permissions/

BMJ Case Report Fellows may re-use this article for personal use and teaching without any further permission.

Become a Fellow of BMJ Case Reports today and you can:

- Submit as many cases as you like

- Enjoy fast sympathetic peer review and rapid publication of accepted articles

- Access all the published articles

Re-use any of the published material for personal use and teaching without further permission

For information on Institutional Fellowships contact consortiasales@bmjgroup.com

Visit casereports.bmj.com for more articles like this and to become a Fellow 